\title{
Introduction: sustainability, innovative milieus and territorial development
}

\author{
Leïla Kebir, Véronique Peyrache-Gadeau, \\ Olivier Crevoisier and Pedro Costa
}

\section{I.1 INTRODUCTION}

Following the crisis of Fordism, which was characterized by standardized production and mass consumption, innovation was brought back to its central position amongst models of economic and social change. Since the end of the 1980s, territorial innovation models (TIMs) (Moulaert and Sekia, 2003) have been the primary reference in public policies relating to innovation and regional and urban development.

This book raises the question of the validity of those models, and particularly the innovative milieus approach, at a time when sustainable development has become the dominant norm in matters of territorial development and innovation. Can these models, constructed in a period when competitiveness was considered as a constraint and a solution to numerous economic and social problems, still account for the processes under way today and, more particularly, for sustainable innovation? Furthermore, factors associated with sustainable development complicate the issue by introducing broader objectives than those of green industry and competitiveness (Truffer and Cohen, 2012). The climate-related, ecological, social and economic difficulties facing today's societies demand innovations (Vollenbroek, 2002) that are able to support the transition towards a sustainable economy and society (Coenen et al., 2012).

In parallel with this shift in social norms, the last 20 years have seen considerable growth in the mobility of capital, knowledge, workers and consumers. Moreover, the development of the Internet and mobile systems has culminated in ubiquitous connectivity, with the result that products, services and economic activities can be continually evaluated by a large community of users, citizens, organizations or experts.

From a spatial configuration dominated by competition between regional systems of production and innovation on a global market, there has been 
a shift to complex and interwoven systems, linking distant points across the globe (Coe et al., 2008). From the local perspective, the problem is to accommodate to this hypermobility, to foster the anchoring of activities and resources, and to find a positioning in this omnipresent media space.

The challenge is how to position oneself in these mobilities while responding to aspirations to sustainability and maintaining, if not improving, economic competitiveness? The way innovations emerge and develop across space and time still demands scrutiny (Zuindeau, 2006). For some (Camagni et al., 1998), the local and the territory are where experiments and innovations in sustainable development are most likely to occur. However, how they are linked to extra-local networks and how they fit into the multi-scale sociotechnical transition (Smith et al., 2010) are questions that remain largely unexplored.

This work presents a dozen case studies on sustainable innovation, ${ }^{1}$ conducted by teams of different nationalities: French, Spanish, Portuguese, German, Italian, Swiss, Dutch and Japanese. The approach is simultaneously theoretical, empirical and comparative. In theoretical terms, this research takes up the theory of innovative milieus (Crevoisier, 2004; Camagni and Maillat, 2006) which evidenced the relationship between innovative activities and territories. This research shows that subject to a number of adaptations - innovative milieus can account in an original way for the dynamics of sustainable innovation and territorial involvement in the transition to a sustainable society. Within the European Research Group on Innovative Milieus (GREMI) framework and the ASLInn programme ${ }^{2}$, common research hypotheses were constructed for the exploration of case studies. This Introduction offers a comparative synthesis of that research.

What is a 'sustainable' innovation? In our research, we adopted the 'actually existing sustainability' approach (Krueger and Agyeman, 2005; Fischer et al., 2007), which considers innovations that are presented, generally by their inventors, as solutions to sustainability issues. It is therefore not a normative approach; in other words, it is not interested in whether innovations are 'really' sustainable. Measuring sustainability is a complex exercise and at present there is no widely accepted method, even in the case of relatively simple criteria such as energy efficiency. In principle, the effects of these innovations should be measured in the future, in terms of their impact on the state of the planet. This is of course not possible in advance or in the short term, and is particularly complicated in the case of experimental initiatives, novel ideas whose impact on the global environment or long-term behaviours is unknown. Although sustainability is a claim primarily made by the promoters of such innovations, it is nevertheless possible to explore the processes whereby they emerge, both 
as economic models and as socially valued projects. That will be the subject of section I. 2 of this Introduction. In section I.3, on the basis of the case studies presented in this book's different chapters, we propose a comparative framework for the analysis of sustainable innovations. This analysis is based on descriptive criteria for the innovative dimension of the processes that drive sustainable innovation. The aim is also to characterize their relation to space and their territorial anchoring. Section I.4 returns to the innovative milieus that drive these sustainable innovations. It consolidates the idea of broader milieus advanced in previous investigation (PeyracheGadeau et al., 2010), and confirms the increasing complexity of innovation issues. The analysis also emphasizes the central role of milieus in anchoring mobile resources.

\section{I.2 THEORETICAL APPROACH TO SUSTAINABLE INNOVATION}

The case studies we conducted were extremely diverse, ranging from new conceptions of green construction in Germany, the establishment of collaborative systems for electric cars in the Basque Country, sustainable finance in Geneva, to waste management projects in a central district of Lisbon. A factor common to all these innovations is that they establish a close and renewed connection between, on the one hand, a much greater diversity of financial revenues than traditional innovations and, on the other hand, rhetoric and debates that seek to legitimize and capture those revenue streams.

\section{I.2.1 Increased Diversity in Business Models}

Innovation is a way to maintain a competitive position or create a competitive advantage, or to retain a strategic position on the market (for example by imposing new technical standards). In this conception, the dynamics of innovation are essentially driven by the supply, supported by technological expertise. The studies that characterize sustainable innovation from this supply perspective essentially focus on eco-technologies (Vollenbroek, 2002; Hamdouch and Depret, 2012; OECD, 2009). The aim of these technologies is better environmental performance; that is to say, meeting the same needs with less impact on nature, or saving resources and energy. These innovations were strong priorities in the Lisbon Treaty and continue to be supported by institutional arrangements in sustainable development policies. They are therefore characterized by revenues earned through the sale of goods and services on the market with - in many cases - the 
addition of public subsidies. Environmental performance is the target of a set of normative systems, either created or in the process of creation (hence themselves embedded in a set of institutional innovations ${ }^{3}$ ), which frame the experimental nature of these eco-innovations.

Other arguments in favour of sustainable innovation, on the demand side, emphasize new needs, desirability, society's aspirations for new forms of consumption and new practices, which are also drivers of sustainable innovation. The new standard of responsibility is cited not only on the production side, but also with regard to consumption. Consumers may be ready to pay extra for certain products that are more 'responsible' than others. This is, for example, at the heart of the debate on sustainable investment funds: the inclusion of extra-financial analysis, relating to the social and environmental dimensions of investments, prompts customers to pay for these services despite the fact that they generate no additional profit. Finally, many sustainable innovations have an experimental and demonstrative function. The entrepreneurs who propose these projects hope to obtain public contributions to support their initiatives and also to boost their image. Solar Impulse, for example, a project for a solar plane capable of flying round the world, is supported by public funds and sponsored by a major bank, which piggybacks on a project with a high media profile to foster an image of environmental responsibility.

We can see, therefore, that in addition to traditional revenues from the trading of goods and services on the markets, together with support for precompetitive research, entrepreneurs producing sustainable innovations can obtain other kinds of revenue that can only be understood by reference to the sociocultural dimension of sustainable innovations. Moreover, sustainable innovations also generate image-related externalities for sponsors, politicians and public organizations.

To sum up, the revenue streams through which so-called sustainable innovations are introduced and perhaps survive are highly diverse and mutually reinforcing. We are a very long way from the traditional commercial model of 'payment for services rendered'. Indeed, a number of flows (financial or in-kind) have no direct monetary counterpart. Some correspond to beneficial indirect transfers, whether in the form of improved quality of life or enhanced image. These innovations have the peculiarity of combining very diverse forms of financing and remuneration, forming complex income models (Ng and Yip, 2010) or business models (Osterwalder and Pigneur, 2013) in which economic value is tightly bound up with the social and cultural values of responsibility. 


\section{I.2.2 Sociocultural Forms of Value in Sustainable Innovations}

Representations of sustainability are very heterogeneous, but they generally refer to the same social norm of 'responsibility' (Gabriel and Gabriel, 2004-2005; Ingham, 2011). From a normative perspective, sustainable innovation is the translation of a requirement to 'do something' for the future of the planet. While there is now a large consensus over this imperative, there is no unanimity regarding its content (what to do). This can partly be understood by the fact that sustainable development necessarily places the objectives in a distant future, on a planetary scale and within a systemic perspective. So with the exception of a few simple cases, there is no practical possibility of measuring the effectiveness of these sustainable innovations. Moreover, there is no consensus over which are the right analytical dimensions and variables to measure. Even photovoltaic panels arouse debate over whether the embodied energy that goes into their production, transport and installation should be included, and how. As there is no agreement over what should be done, the requirement to act entails another injunction: to behave responsibly. The entrepreneur in sustainable innovation is therefore also a moral entrepreneur (Becker, 1973), defending these values of responsibility and seeking to be recognized as such. However, this grand status is not something that can be selfattributed. It is the outcome of a social process of valuation (Beckert and Aspers, 2011; Stark, 2011) which mobilizes a variety of gatekeepers - the media, the local community, sponsors, celebrities, green politicians, nongovernmental organizations (NGOs), monitoring institutions, and so on (Jeannerat and Crevoisier, 2011) - who may also be prompted to condemn behaviour that they consider 'irresponsible'. When positive, the reputation that they help to build can have significant ripple effects and serve as an example for others.

Demonstration projects (Späth and Rohracher, 2012) are sustainable innovations that have powerful value as examples ${ }^{4}$ and may even be completely devoid of functional utility. These projects always place the emphasis on communication and attract subsidies from public authorities and contributions from research institutes, which reorientate their work in this direction and, in return, acquire legitimacy with their voters and general political acknowledgement. The same is true for private sponsors ${ }^{5}$ and the media, which boost their image and audience by spotlighting these projects. Finally, users, citizens, audiences or consumers can lend their support and/or their expertise to projects, thereby confirming their cultural value or even their financial valuation. ${ }^{6}$

A sustainable innovation can therefore be defined as a set of objects and transactions between different actors based on a projective approach 
towards a better (in the sense of environmentally friendlier, socially fairer, economically more viable) future for the planet, even if perceived at a local level. The economic value of a sustainable innovation depends not only on the embodied components of the transaction, but also on its embeddedness in a culture of responsibility where legitimizing gatekeepers (journalists, NGOs, experts) play a crucial role.

\section{I.3 TOWARDS A CHARACTERIZATION OF THE DIMENSIONS OF SUSTAINABLE INNOVATION}

On the basis of the comparative analysis of case studies presented in this volume, we propose to distinguish four dimensions of sustainable innovation that will dominate to varying degrees from one case to another: product-oriented innovations, institution-oriented innovations, flagshiporiented innovations and territory-oriented innovations. Three groups of criteria habitually used in the territorial approach are employed to characterize these dimensions: the technical criteria of sustainable innovations (content of the innovation, associated conception of sustainable development, aspects of sustainability emphasized and performances anticipated), socio-institutional criteria (actors involved and forms of coordination) and territorial criteria (how the innovation is spatially embedded, the location strategies observed and the forms of anchoring associated with it).

These dimensions are not mutually exclusive, but can be found simultaneously within a single project. The objective, therefore, is not to contrast them, but to show what each one entails in terms of sustainability and territorial organization. Table I.1 presents these different dimensions of sustainable innovation.

\section{I.3.1 Product-Oriented Sustainable Innovation}

Sustainable innovation in products (or services) has similar features to classic industrial innovations. In fact, companies and other production systems have largely adopted sustainability priorities to renew their range, develop new niche markets or simply revise their promotional pitches. Innovations in products and services include: investment funds based on financial, environmental, social and governance criteria (Livi et al., Chapter 1); engineering and architecture services specializing in energyefficient renovation (Kebir, Chapter 2) and in sustainable construction (Strambach and Lindner, Chapter 3). These new products and services are intended for sale on the market. In most of them, it is the dimension of economic and environmental sustainability that is emphasized. 


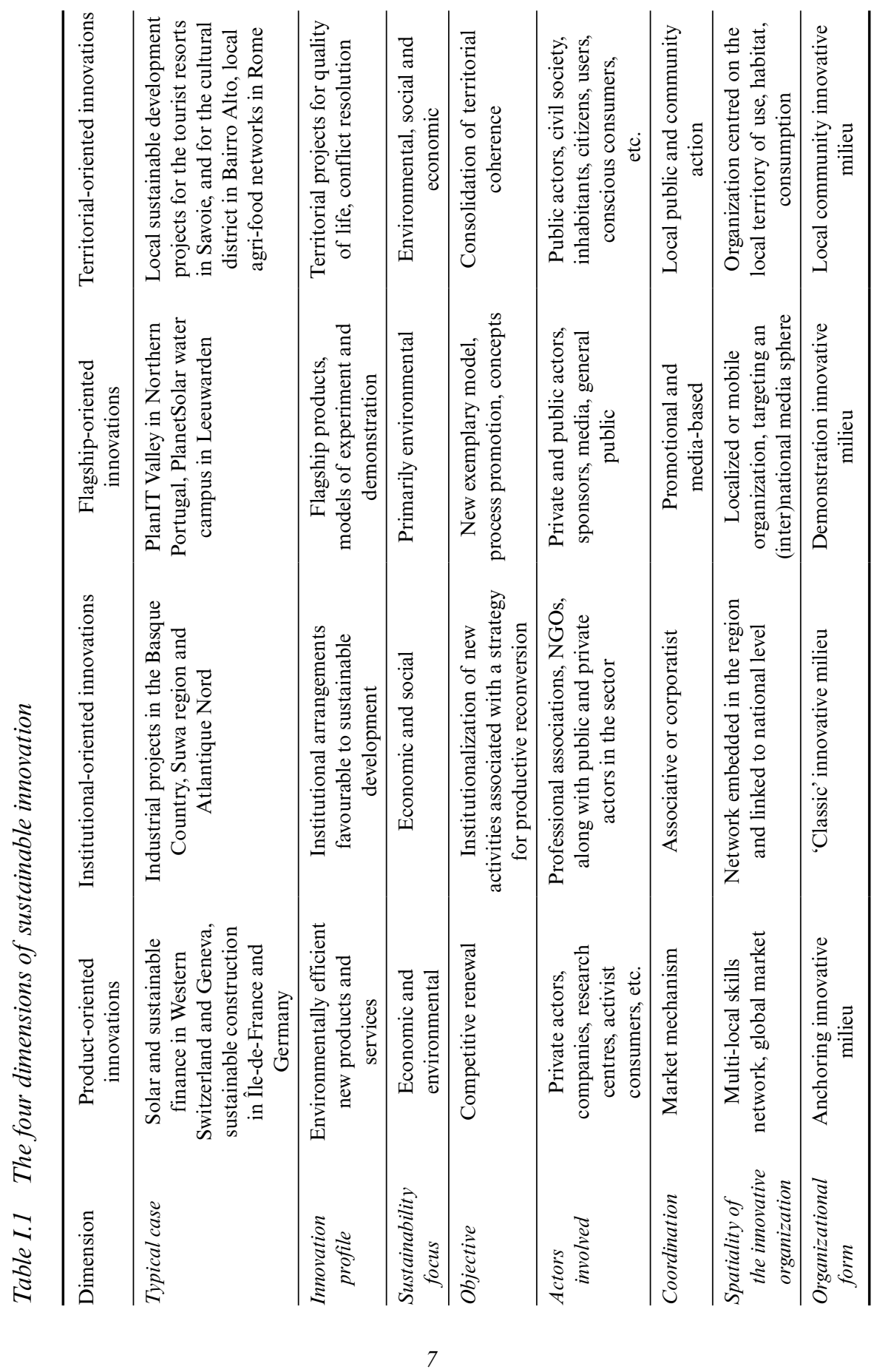


In several cases, institutional arrangements (laws, agreements, regulatory frameworks, various plans pursued under international agreements, and so on) play an important role. These arrangements have a number of effects: they help to create markets or to add value to the products (for example, sustainable renovation and compliance with existing climate plans); they legitimize 'alternative' approaches or professions and thereby provide them with a (brief) competitive advantage; they encourage the formulation and spread of these practices and sometimes, according to certain criticism, simplify them to the detriment of the initial spirit (this can be clearly seen in sustainable renovation). The project backers are mainly private firms, either small and medium-sized organizations (SMEs) or large companies, supported by research centres and public support institutions, customers (notably NGOs, users and activist consumers), and so on.

These primarily local networks contribute to the reduction of the field of possibilities so that the product or service can be concretely defined. Sustainable finance in Geneva (Livi et al., Chapter 1), for example, is developed under the 'control' of NGOs or rating agencies. The sustainable renovation of a building is the outcome of continuous negotiations between the building owner, project manager or technical teams, certifying bodies and, in certain cases, users. There are also multi-actor projects where public demand, by providing outlets, allows innovation to develop within a territory. The development of electric vehicles in the Basque Country is a typical example of this type of process (Del Castillo et al., Chapter 9). It is a 'quadruple helix' project between a company (Mercedes), the region, the developers (research and development) and the future user tasked with marketing the vehicles (public or private operator) through a car-sharing type system.

The dominant institution in product-oriented sustainable innovation is the market. The process here is not a simple quantitative adjustment between supply and demand, but a range of coordinations to devise, design, produce and sell a product or service in return for payment. The paradigm here is still competitiveness and relations of competition and cooperation, through which the actors concerned can innovate and obtain revenues.

Indeed, the organization of the innovation process operates within the framework of networks rooted in territorialized systems of production. Nevertheless, the intensification of two-way spatial flows of knowledge and capital, together with the development in the 1990s of multi-local ways of organizing production, now demands new capacities of local actors. The first is the capacity to connect - via international networks to the knowledge and capital needed, and to identify potential partners and opportunities for the territory. The second is the capacity to integrate 
and thereby to anchor (Crevoisier and Jeannerat, 2009; De Propris and Crevoisier, 2011) this knowledge and capital and these opportunities in the territory. This is a step beyond conventional external relations or so-called 'pipeline' phenomena (Maskell et al., 2006), well known and previously identified in systems such as clusters, industrial zones, innovative milieus, and so on. The intensification of two-way flows of knowledge, in particular specific and symbolic knowledge, makes the systems more complex. However, what characterizes the current dynamics of external exchange lies precisely in the organization of production, which is now multi-local. Made up of productive combinations between international scale systems of specialized production, these forms of organization rely on greater integration between systems of production, ultimately constituting global production networks (Coe et al., 2008). Case studies on sustainable innovation have shown the existence of anchoring milieus; in other words, local dynamics of actors capable of generating the capacity described above.

The spatiality of these sustainable innovations is global, in the sense that they are essentially the outcome of multi-local and international networks of skills. Territorial anchoring takes place through the reinforcement of local resources and their linkage with knowledge and capital originating in external relations, a kind of combination that nowadays poses no problem. In any case, local provision of all the resources needed (in particular, specific and symbolic resources) is simply no longer realistic, given the diversity of those resources and the rapidity of production cycles.

\section{I.3.2 Institution-Oriented Sustainable Innovation}

Institutional innovations are innovations that entail modifications in the rules or processes of interaction between actors within innovative organizations. They can take two forms. The first form is the establishment of associations or professional groupings - at regional and/or national scale - that initiate measures to energize the milieu (notably by means of professional support initiatives, fairs and exhibitions, the creation of dedicated media). Examples are the Basque Country and the implementation of a strategy of regional development (Del Castillo et al., Chapter 9) and the cases of the creation of the Atlantic Nautical Network in France (Guesnier, Chapter 10), and of the SUWAMO development agency in Japan (Sato and Okamoto, Chapter 11), which have been established to encourage the interregional promotion of sustainable development in the industries and territories concerned. These promotional systems also sometimes include communication and lobbying activities directed at politicians and the public with the aim of influencing laws, regulations, public policies and practices in favour of sustainable development. For example, 
Swissolar is an umbrella structure for actors interested and involved in photovoltaic power, and seeks to promote laws in favour of energy transition. Sustainable Finance Geneva is a locus of exchange, but also for the recognition, labelling and communication of new, so-called sustainable, financial practices. We find in these organizations not only companies and research centres with an interest in the domain, but also NGOs, activist citizens or consumers, even public authorities.

The second form of institutional innovation is precisely the amendment of the laws and regulations that frame the implementation of sustainable development. In many cases, this innovation occurs through lobbying by organizations and professional groups seeking to encourage new sustainable development-related markets or technologies. Changes in standards, for example in the construction industry, are of this kind.

Institutional innovations are often multi-scalar. They can be driven by the need to transpose national or international legislative changes to a regional scale or, conversely, to promote laws or standards at a regional level that favour targeted local activities in sustainable development.

The regions in which such innovations take place are mostly characterized by challenges to territorial production systems (loss of competitiveness, compliance issues). In these circumstances, sustainable development and the market it represents become a primary focus of investment, when this is not forced upon the industry concerned by the need to upgrade its standards. Here, the objectives of sustainability are primarily socioeconomic. Economic sustainability is important. At stake is the future of whole regions characterized by the presence of old industrial production systems, which like the Basque Country (Del Castillo et al., Chapter 9), the region of Suwa (Sato and Okamoto, Chapter 11) and the Atlantic Nautical Network (Guesnier, Chapter 10) have experienced periods of crisis and recovery, and are now gearing up for a new 'round' of competitiveness. However, while sustainable development is present in all three of these cases, it is clearly formulated in the European cases, but less so in the Japanese case, although sustainable development in Japan is identified as a promising sphere for everything to do with energy performance and medical services geared to quality of life. Indeed, in Japan, innovation in quality of life, and particularly human well-being, is part of the anticipated benefits of sustainable development in the same way as 'green innovation', thereby opening the way to the medical sector and healthcare services. Moreover, the companies in the Suwa region (Sato and Okamoto, Chapter 11) have a long tradition of activity in precision machinery, so find here opportunities for developing new products that combine service solutions for individuals and renewed outlets for these industries (for example, alarms for patients with dementia). 
Sustainability is above all tackled at the scale of the region and the production systems concerned, even though the approach to sustainable development is in fact the same as that defined at the global scale. The paradigm here still remains that of competitiveness: targeting growth and thereby regional development (and/or economic sector vitality) by supporting basic activities. More than business competitiveness alone, what is at stake here is the competitiveness of the territorial systems or sectors concerned. The performance sought is therefore primarily economic, though with a social component (and a political strategy) relating to the future of populations and their living conditions. In the Basque case, it should be noted that environmental questions (reducing industrial pollution) were at the heart of the 1980s conversion programme.

The players driving these innovations are institutional, associative (professional organizations and NGOs), public and private actors originating in public authorities, in partnership with chambers of commerce and/or private companies. In the three cases studied, these strategies or systems encourage the development of new 'related variety'7 combinations of activity, operating throughout an extended chain of production. In this respect, they confirm the hypothesis that sustainable development leads to greater trans-sectoral linkages in production.

The systems introduced seek to stimulate or reinforce 'classic milieu' type dynamics. The aim is above all to reinforce the local base and productive combinations between the sectors already present, even though they all operate in a globalized world of external exchanges. In terms of spatiality, the innovative organization that drives institution-oriented sustainable innovation forms a network structured on a regional base. The process is steered within this network, even though central government can be involved through its general (sustainable development policy, industrial policy) or sectorial policies.

\section{I.3.3 Flagship-Oriented Sustainable Innovation}

Amongst the forms of sustainable innovation analysed, flagship-oriented innovation is the one that seems to differ most from classic innovation processes. These innovations generally exhibit economic and technical performances that are quite distant from conventional conditions of use. Their purpose is to set an example or even to educate. Their primary goal is media visibility. They work intensively through the media-symbolic spheres and therefore through actors in the system of consumption. ${ }^{8}$

Flagship sustainable innovations are projects that are ambitious in their innovation goals. They may be precursors of new resource management practices (sustainable renovation in Île-de-France; Kebir, Chapter 2), 
showcases for professions (the PlanetSolar ship; Livi et al., Chapter 1), initiatives that demonstrate the potential of a sector (the water campus in Leeuwarden; Ebbekink and Lagendjik, Chapter 5) or of a new urban concept (a new town project, Plan IT Valley in Paredes; Carvalho et al., Chapter 4). The function of these large-scale projects is to provide anticipated new services, publicized through the media as a demonstration that 'it works'. In this respect, they constitute a real-world locus of experimental, technological and organizational solutions to sustainability questions. So when the PlanetSolar ship succeeds in sailing round the world, it demonstrates that photovoltaic technologies can achieve feats of sea travel comparable with the performances of traditional fuels.

While life-size test processes have always existed, along with practical tests on new solutions, there are several factors that set these projects apart as objects specific to our era. The exemplary aspect of these sustainable innovations, conceived as unique and pioneering experiments, is an integral part of the product. These innovations are not usually intended to be reproduced in the same form. On the contrary, their goal is singularity, specificity. They are not prototypes. It is the solution, not the product, that is intended for subsequent standardization and dissemination. This is apparent in the Paredes 'new town' in Northern Portugal, with its Urban Operating System ${ }^{\mathrm{TM}}$ platform primarily designed for the efficient management of urban flows (for example, energy, transport). The idea is then to design standard software applicable to other places and other scales, with new town projects envisaged and selected for the testing of this software in different environments (Carvalho et al., Chapter 4).

The flagship innovations studied have a certain dimension of technological progress and are also designed to be the symbols of virtuous sustainability solutions. In this respect, for the public they are not only vehicles for the promotion of new solutions to environmental challenges, but also a way to construct meaning around those challenges. In terms of sustainability, the stated objectives of the projects observed are primarily environmental (reducing the negative externalities of urban congestion, combating climate change, and so on). The scale of action sought depends on the innovation and its potential scope, one that is clearly global for the Swiss and Portuguese projects (Livi et al., Chapter 1 and Carvalho et al., Chapter 4).

In organizational terms, these innovations are driven within networks that encompass private actors from different sectors, public actors, sponsors, users and, more broadly, the media and the general public. This means that the business model in these projects is not always easy to identify, and is undoubtedly a long way from the conventional scheme in which a product is sold in return for payment. Nevertheless, the innovations exist 
and generate income streams. If we look at the two 'private' projects, PlanetSolar and PlanIT Valley, we observe that they survive on direct or indirect subsidies (funding by the associated research), on sponsorship, on subscription (PlanIT Valley) and on revenues from services rendered and from the media (Livi et al., Chapter 1). The forms of organization observed here are rooted in a milieu, in particular an anchoring milieu (Crevoisier, 2016), combined in certain cases with 'top-down' dynamics. They are significant projects which mobilize knowledge (particularly technological and symbolic), capital and opportunities that can originate in international networks. Being relatively footloose, they will locate wherever local actors are keen for them to come. Finally, these projects may be invited by certain local actors without any real prior involvement by the parties concerned and in this respect may be said to be imposed on the territory (for example, the water campus in Leeuwarden; Ebbekink and Lagendijk, Chapter 5). Their primary characteristic is their 'demonstrative' function.

Insofar as these projects are anchored in a territory, the anchorage is above all symbolic in that they bring media visibility (specialized or mass media). The clearest example is the PlanIT Valley and the town of Paredes in Portugal (Carvalho et al., Chapter 4): whether the new town becomes a reality or not, whether it is a success or failure in terms of performance, Paredes will always be associated with the project, in any attempt to show whether it succeeded or failed. And if the town never comes into being, the software platform project exists, jobs have been developed and milieu type dynamics are beginning to emerge. Also noteworthy is the strong commitment of local and national actors around this project to facilitate its realization. The same symbolic anchoring is found in the case of PlanetSolar's boat (Livi et al., Chapter 1) which, although built to make a trip around the world to demonstrate the possibilities of solar technologies, remains linked with its territories of origin (Western Switzerland for the design, Northern Germany for the construction). So the more international the project is in scale, the more important is the territory as a piece of the global puzzle and part of a multi-local network.

Not every territory is necessarily capable of deploying this type of project. It depends on the local actors' capacity to connect to the international networks that support them or provide the resources necessary for projects on this scale (technological and symbolic knowledge, financial conditions). 


\section{I.3.4 Territory-Oriented Sustainable Innovation}

Here, the primary focus of the innovations is the 'common good'. The objective of projects in this category is to improve the living conditions of residents and users. The approach to sustainability is broader than in the previous cases, encompassing the environmental, economic and social dimensions of sustainable development. The notion of sustainability is principally considered at local scale. What matters is above all to consolidate territorial coherence.

In Rome, for example, the goal is to support periurban agriculture, with an emphasis on agri-organic practices (De Rosa and Trabalzi, Chapter 7). In Savoie, the actors in the tourism sector are thinking about the future of their resorts as holiday destinations but also as places to live (PeyracheGadeau et al., Chapter 8). Likewise, in the Bairro Alto neighbourhood, the objective for the local players is to minimize conflicts of use and maintain the neighbourhood's quality of life (Costa, Chapter 6). In all three cases, behind the innovations is the need to tackle a situation of difficulty or crisis, to maintain cohesion against a collective threat. In some cases, these projects have the effect of crystallizing certain tensions and resolving conflicts of use. Local government plays a crucial role in this, often alongside institutional and incentive systems introduced at larger scales (for example, the Rio Conventions and Agenda 21), and with civil society, exploiting grassroots dynamics. This means that numerous players are involved: public actors, private companies, civil society (notably residents, citizens, users, conscious consumers). This increased involvement by local communities demands specific forms of territorial governance, which is perhaps one of the features specific to these 'sustainable' innovations.

The dominant institutions here are local public authorities and community actions, insofar as it is through these that innovation takes place. Municipalities and local associations provide places for meeting, project formulation and negotiation, where preoccupations relating to sustainable development can take concrete form. The goal of innovation, therefore, is not to establish some competitive advantage on the market, but primarily to solve environmental and social problems identified as such by the community.

The forms of organization behind these innovations are locally anchored and have strong links with the local community and grassroots movements. In addition to the private and public actors, they involve other civil society stakeholders and thereby the potential for specific forms of governance. They are characterized by network type dynamics (both formal and informal, often based on untraded interdependencies) within which, as time goes on, the project and its coordination will be constructed. 
The spatiality of the project is that of the local or regional territory. Indeed, in these cases the scope of the innovations extends no further than the circle of local actors (even if they are replicable in other contexts). What is at stake is the renewal of the foundations of the territory, the traditional bonds between the actors and their relation to the surrounding space.

What is interesting about these sustainable innovations is that they reinforce the complexity of the relations between actors and between activities. For example, the 'Zero Km' project in Rome (De Rosa and Trabalzi, Chapter 7) connects restaurants with local producers, re-establishing lost links. These innovations are anchored because of the tissue of local socioeconomic relations. They weave connections between the territories of habitat, production and consumption. In parallel they can make actors in the territorial system aware of their own potential for civic mobilization and collective action to overcome their challenges and the inadequacies of individual or public-driven action (Costa, Chapter 6).

Ultimately, these four dimensions of sustainable innovation possess characteristics that offer a new idea of innovation. Sustainability expectations combine environmental, social and economic priorities in new and different ways from one type of innovation to another. It is also the variety of the actors and the forms of governance that makes innovative projects hard to manage, notably with the increased role of professional associations, NGOs, media, consumers, public-space users, firms, citizens and public actors. This diversification also affects relations to the space of territorial location and embeddedness. Organizations made up of networks of actors, formally or informally settled, are structured at different scales and on multi-site principles. Yet within these networks the relation to the local endures, or even may sometimes be reinforced, as a relevant scale at which to give impetus to initiatives. This hypothesis takes us back to the question of the relevance today of the innovative milieus approach.

\section{I.4 INNOVATIVE MILIEUS AND SUSTAINABLE INNOVATIONS: TOWARDS A NEW THEORETICAL PROPOSAL?}

The innovative milieu concept provided a useful analytical framework for understanding the link between sustainable innovation and territory. What constitutes the innovative milieu is essentially a set of actors who form an organization centred on an innovative project. This approach considers the situated nature of the coordination of the innovative project and 
the networks that are structured out of it, on a local base with extra-local extensions or connections.

How far is this conception of the innovative milieu applicable to sustainable innovation? We propose now to discuss the specific features identified in the milieus dealing with sustainable innovation. By looking at the spatial forms these innovations take and how they are anchored, we end this chapter with a redefinition of the territorial content of innovative milieus.

\section{I.4.1 The Innovative Milieus that Drive Sustainable Innovation}

From a comparative analysis of the case studies, we can associate each dimension of sustainable innovation with forms of productive organization and associated milieus (Table I.1). A first observation arises out of the nature of the actors involved: the milieus observed are multi-actor organizations. They include companies and research and development (R\&D) departments, but the system of actors goes much wider. Sustainable innovation would seem to be a collective construct that involves a much broader range of partners than those usually involved in the classic innovative milieus described in the 1980s.

Indeed, what the case studies in this volume show is that the entrepreneurial figure is no longer restricted to the firm and its members (managers, designers, 'decision-makers' of the industrial world); new actors have joined the processes of innovation: policy-makers, the media, civil society actors (associations, NGOs), even 'activist consumers'. In the Alps, for example, users of winter sports resorts have formed an association (Mountain Riders) which promotes initiatives designed to foster responsible behaviour (cleaning operations on very busy sites, preparation of a 'resort eco-guide') (Peyrache-Gadeau et al., Chapter 8).

In the case of anchoring milieus (product-oriented innovation), innovation takes on a wider meaning: while remaining focused on production and formalized through new products or processes, it often brings stakeholders into the design process. When this happens, it becomes the expression of a broader rationale, which combines short- and long-term economic values, along with environmental, social and cultural value; it also expresses the different motivation of the agents driving the innovation, be they the producers, the consumers, users or gatekeepers.

The milieu in which 'flagship' innovation develops (demonstration milieu) is in a sense a 'mediatized', publicized version of sustainable innovation conceived simultaneously as a promotional tool and an experimental object. With its focus on sponsors, advertising agencies and media outlets, the collective operates an economy of marketing activities. The milieu no longer has the classic contours of the entrepreneurial milieu, but is 'reconfigured' 
in the sense of the importance assigned to form (as understood by designers, creatives and image professionals).

When its focus is institutional creation (classic milieu), innovation drives the anticipated changes relating to sustainable development (notably: new standards, new systems, new organizations). Its aim is to revitalize wellembedded production systems through agreement with actors in the public, private and associative sectors interested in protecting and regenerating local and regional industry.

Sustainable innovation in all three of these milieus reflects the incorporation of environmental performance or social responsibility into the innovation process, a process that legitimizes the arrival of new actors into the milieu, self-described or identified as experts in challenges and problems of these kinds.

In the local community innovative milieu, the actors involved are of a quite different nature: purveyors of common sense, citizens, and conscious consumers. In a context of strong pressure for participation or consultation, they are 'summoned' in the name of civil society, the users of public services, citizens or inhabitants. They become engaged in the innovation process by a variety of methods of selection of varying formality (appointment, election, volunteering), and above all, their contribution is in principle recognized not in an individual capacity, but as the embodiment of the interests of different collectives. In this sense, the governance of the milieu is of a different type. It focuses the resolution of collective problems, the overcoming of conflict, the quest for solutions to vulnerabilities, or more simply the prospect of a better quality of life or better public services. Here, the sustainable innovation itself is of a fundamentally different nature, defined in terms of the quest for consensus in the name of public interest, and deeply rooted in the community.

All four types of milieus are marked by the presence of public actors. They intervene as 'partners' in the entrepreneurial milieu through the funding of research, the provision of education, technology transfer or the dissemination of knowledge. They sometimes intervene directly in the innovation process as entrepreneurs in a number of public sector domains (energy, transport, planning, urbanism) where sustainable innovation is at present of particular importance. Public actors may also intervene in sustainable renovation through incentives or regulations. They can foster the decision to innovate, may be the initiators of innovative projects, or may intervene through public support, in the case of subsidies, indirect incentives or public tenders. Once an innovation is implemented, it may instigate competitions or labelling systems that establish the legitimacy of the sustainable innovation (Theurillat and Crevoisier, 2012).

Note that it is the local community milieu where the role of the public 
actor appears particularly central. Not only is it generally the instigator of the commitment to innovate, but it also provides the impetus to organize the milieu and to identify the stakeholders (generally through its choices about the composition of the system of actors). Here, it is often (but not necessarily) the decision-makers on behalf of the public interest and, legitimized by its elective status, it embeds that interest through participatory arrangements. The public actor's leadership position in the milieu lends the sustainable innovation particular value, as it is implemented in the name of the public interest.

\section{I.4.2 Spatial Forms of Innovative Milieus: Mobility and Anchoring of Sustainable Innovations}

One element in the comparison of the forms the milieu takes is the spatial configurations of the partnerships and networks constituted via the interactions between the actors involved. This criterion for the identification of innovative milieus follows on from GREMI's earlier work, which characterizes the innovative milieu as an organization of actors that is anchored in a local or regional territory and mobilizes the networks of innovation that structure it, but which also goes beyond that territory and contributes to its expansion and interweaving with other territorial scales (national or international) (Crevoisier, 2004; Camagni and Maillat, 2006). These interdependencies between actors and different spatial scales are underpinned by alliances and relationships of trust, forming bonds between the different groups of actors (for example, academics, entrepreneurs, administrations, institutions and civil society, media) which enable them to pool their ideas and actions and thereby to create synergies whose fruits can be shared. In this respect, the milieus identified resemble the classic innovative milieus observed in the literature. What sets them apart is the links that sustainable innovation networks form both locally and extra-locally. The sustainable innovation networks defined in the typology above are all founded in the local or regional scale. In the local community milieu, the local and regional dimensions combine because of the leadership exercised by the public and/or collective actor which embodies territorial authority or community will. In the case of the anchoring milieu, the local dimension is mobilized through innovation networks that create connections between multi-local forms. In the case of the classic milieu, the local combines with the regional and national scales through the system of institutional processes that develop simultaneously at all three levels, notably through different sustainable development measures and in the quest to establish coherence between them. Finally, the demonstration milieu relates to organizations in which the local links are weak, though nevertheless 
identified by a geographical origin, and which are more oriented towards large-scale extra-local networks with the capacity to propagate an image, if possible at global scale.

\section{I.4.3 Towards Milieus with More Complex External or Internal Exchanges}

The forms of organization identified above can be completed by the analysis of the modes of anchorage of the dynamics generated by sustainable innovation. Anchoring milieus are organized on a basis of multi-local, productive sustainable innovation. This innovation articulates both the productive combination and the economic dynamics that arise from it. The network of actors forms to pool the skills that drive sustainable innovation, which are often highly specialized and spatially dispersed. The network helps to form this collective intelligence needed to improve environmental performance (and reputation) in a multi-local space.

In classic milieus a system of material and institutional anchoring is used to fix, locally - in cities and regions - not only the knowledge resource but also the practices needed to amplify the forms of collective learning relating to the production of knowledge. The new institutional frameworks promote joint action by the actors and new economic practices, which are more collaborative and favourable to the exchange of tacit knowledge on a local or regional basis and linked with systems developed at national level. The sustainable innovation network is a way to coordinate local or regional and national initiatives and the institutionalization of the relations between actors, although the dynamics are deployed at local or regional level.

The same is true for local community milieus which, within the local territory, exploit the interplay of public, private and collective logics of actors involved in different capacities in the sustainable innovation network. Finally, demonstration milieus rely on projects that can be either localized or itinerant. The degree of localization is weak and, as a result, the dynamics generated by the innovative process are also weakly anchored.

In each of these forms of innovative milieu, access to knowledge is highlighted as an essential element in sustainable innovation processes, a resource that has become genuinely strategic. The milieu allows this resource a temporary anchorage, and can even help to specify it by facilitating its spatial concentration within dedicated hubs. These hubs can temporally take a cluster form when sustainable innovation requires strong geographical proximity between the actors involved and the knowledge resources mobilized. However, the innovation network will necessarily remain open, in order to retain its capacity to mobilize new skills. 


\section{I.4.4 Processes for Anchoring Innovation Dynamics in Territories}

The theoretical proposal that emerges from this comparative analysis is as follows: sustainability generates anchoring processes that are activated by the innovative milieu. We are witnessing the emergence of a new level of multi-local organization in innovative milieus.

In terms of the configurations of the milieus observed, two situations characterize territorial anchorage: either the dynamics are 'naturally' linked to the territory (local or regional), or they are not automatically so linked, and operate at multi- or extra-local scales, in which the milieu nevertheless acts as an anchoring instrument by capturing and fixing the resources deployed. The first situation is illustrated by the electric car cases studied in the Basque Country (Del Castillo et al., Chapter 9): the anchoring of the dynamics is the result of the 'hard elements' (for example, clusters, technical centres), associated with support for regional innovation policies, with the industrial-entrepreneurial legacy and local social capital 'soft elements'. The cases of photovoltaic power in Western Switzerland and the PlanetSolar flagship innovation (Livi et al., Chapter 1) mobilize resources (funding, technological research, sponsorship, and so on) in different parts of the world, combined with multi-local knowledge to develop products and projects that will be simultaneously anchored in the local and be extra-local. The PlanetSolar project, for example, was initiated in Western Switzerland, but is perceived and sold in Germany - where the boat was built - as a German project. Moreover, in every port where it has moored, events and exhibitions have been organized with the local actors involved in these technologies (Livi et al., Chapter 1).

So territorial anchoring is not confined to a single form, the local incubation of the innovative milieu, though this picture is of course relevant in a number of situations where the affiliation of the sustainable innovation with the local socio-productive system is strong. However, anchoring does not have to be a prior state, it can be constructed in the course of the process of innovation by legitimizing the use of certain resources that are finally integrated into the territory of innovation by a process of specification. Indeed, the facility with which remote interactions can now take place within innovation networks prompts each of the actors - as well as the spaces - that participate in the networks to specify themselves in relation to each other very quickly, and not necessarily in cooperation. A fine example of this process is the development of the photovoltaic panels sector. Western Switzerland, which had a number of advantages in the technological field and in specialized production, has seen its entire production move to the Far East and the whole manufacturing machinery sector concentrate in Germany. Western Switzerland retains the cutting-edge research, and 
above all has developed innovations in applications linked to the local and if possible international - market. This also corresponds to profound and evolving specifications, largely imposed by changing costs and local capacity to adjust to those costs.

Here we can perhaps see a genuine renewal in the innovative milieu, which can be conceived not just as single-location entities, open to extralocal ramifications through the medium of their networks, but also as organizations conceived from the start on a multi-local base and interconnected through networks.

\section{I.5 CONCLUSION AND PROSPECTS}

Ultimately, the analysis of sustainable innovations leads to a further development in the theory of innovative milieus. It brings out the importance of this territorial dimension, which is re-examined here in terms of anchoring processes. In circumstances of intensified multi-scale interdependencies, connection to the local would still seem to play a structuring role and we are seeing new forms of local anchoring. The renewal of innovative milieus is also linked with an expansion in the range of stakeholders to encompass the multiple actors and rationales behind sustainable innovation, which brings together private, public and associative sector interests, and stands at the intersection of processes of supply and demand. The innovative milieu is no longer only incubated in the productive system, but is becoming a form with the capacity to expand to multiple collectives of governance, even to the societal scale. We have identified four dimensions of sustainable innovation that reflect different innovation profiles and sustainability objectives, and are constituted on the basis of different actors, organizations and spatial forms.

In this respect, the approach aims to contribute to the identification of the different pathways to territorial efficiency. The innovative milieus described offer ways of analysing the diversity of innovative processes, independently here of any judgement regarding their effectiveness in the evolution of a sustainable economy.

There are answers here to the weighty questions regarding forms of 'good governance' in sustainable development projects: innovative milieus appear as vehicles of a representation of innovation through 'collective action', collaborative interchange, cooperation within systems of actors which can be variable in their geometries and compositions, but share the common characteristic of being territorially (re)anchored.

From a more critical perspective, we must nevertheless emphasize the analytical barriers encountered, in other words the necessity of pursuing the 
analysis of sustainable innovations from the point of view of the difficulties, the incompatibilities, and the failings encountered by the actors and of their plural approaches to sustainability. In particular, research needs to be continued into how sustainable innovations connect with different scales within a single territory. So we will end with the following hypothesis:

For an innovative milieu to be sustainable today, it needs to encompass the four dimensions of sustainable innovation identified. In particular, it needs to seek explicitly to unite the aspects of territorial quality of life, protection of resources and economic development; it must notably be capable of integrating successfully into multi-local networks and into the symbolic functions that have become central to the development of territorial systems of production.

\section{NOTES}

1. See Chapters $1-11$.

2. ASLInn AAP PUCA-MEEDDM 2011-13 Programme: Localisation des activités économiques et développement durable des activités? - 'Anchoring, Sustainability and Localisation of Innovation: Towards New Forms of Territorialisation of Economic Activities' (ASLInn). See Kebir et al. (2012).

3. For example the creation in 2006 of the Environmental Performance Index (EPI), the European Eco Management and Audit Scheme (EMAS) or ISO 14000 relating to the environmental management system, Association Française de Normalisation (AFNOR) systems such as 'Calculation method for assessing the environmental performance of buildings' (standard NF EN 15978, which took effect on 18 May 2012), or else the European Directives establishing a framework for setting eco-design requirements applicable, for example, to energy consuming products (Directive 2005/32/CE of the European Parliament and European Council of 6 July 2005), through to eco-labels and eco-certification.

4. This book include examples of such innovations which carry value, such as projects for a solar boat capable of circumnavigating the globe (see Chapter 1), or else the Paredes model city project (PlanIT Valley in Northern Portugal; see Chapter 4) which promotes integrated digital urban management.

5. As with the case of the participation of oil companies in electric car projects (see for example the development of electric vehicles in the Basque Country; Chapter 9).

6. This situation is illustrated in particular in this book by the cases of the electric vehicle in the Basque Country (see Chapter 9), of the agri-urban networks in Rome (see Chapter 7), of tourism in Savoie (see Chapter 8), and sustainable innovation in Île-de-France (see Chapter 2).

7. See Asheim et al. (2011)

8. The system of consumption encompasses all the actors involved in the distribution and dissemination of a product or service. It includes the networks of distributors, consumer associations, users, the media and so on (Jeannerat and Kebir, 2010). 


\section{REFERENCES}

Asheim, B., Boschma, R. and Cooke, P. (2011), Constructing Regional Advantage: Platform Policies Based on Related Variety and Differentiated Knowledge Bases, Regional Studies 45, 893-904.

Becker, H.S. (1973), Outsiders: Studies in the Sociology of Deviance, Free Press, New York.

Beckert, J. and Aspers, P. (eds) (2011), The Worth of Goods. Valuation and Pricing in the Economy, Oxford University Press, New York.

Camagni, R., Capello, R. and Nijkamp, P. (1998), Towards Sustainable City Policy: An Economy-Environment Technology Nexus, Ecological Economics 24(1), $103-118$.

Camagni, R. and Maillat, D. (eds) (2006), Milieux Innovateurs: Théorie et politiques, Economica, Anthropos, Paris.

Coe, N.-M., Dicken, P. and Hess, M. (2008), Global Production Networks: Realizing the Potential, Journal of Economic Geography 8(3), 271-295.

Coenen, L., Benneworth, P. and Truffer, B. (2012), Toward a Spatial Perspective on Sustainability Transitions, Research Policy 41, 968-979.

Crevoisier, O. (2004), The Innovative Milieus Approach: Toward a Territorialized Understanding of the Economy?, Economic Geography 80(4), 367-379.

Crevoisier, O. (2016), The Economic Value of Knowledge: Embodied in Goods or Embedded in Cultures?, Regional Studies 50(2), 189-201.

Crevoisier, O. and Jeannerat, H. (2009), Territorial Knowledge Dynamics: From the Proximity Paradigm to Multi-Location Milieus, European Planning Studies 17(8), 1223-1241.

De Propris, L. and Crevoisier, O. (2011), From Regional Anchors to Anchoring, in Cooke, P., Asheim, B., Boschma, R., Schwartz, D. and Tödling, F. (eds), Handbook of Regional Innnovation and Growth, Edward Elgar Publishing, Cheltenham, UK and Northampton, MA, USA, 167-177.

Fischer J., et al. (2007), Mind the Sustainability Gap, Trends in Ecology and Evolution 22(12), 621-624.

Gabriel, P. and Gabriel, P. (2004-2005), Diffusion du développement durable dans le monde des affaires: un schéma conventionnel, Revue française de Gestion 152, 199-213.

Hamdouch, H. and Depret, M.-H. (2012), Sustainable Development Policies and the Geographical Landscape of the Green Economy, Actors, Scales and Strategies, Finisterra 47(94), 49-80.

Ingham, M. (2011), Vers l'innovation responsable: pour une vraie responsabilité sociale, De Boeck, Bruxelles.

Jeannerat, H. and Crevoisier, O. (2011), Non-Technological Innovation and Multi-Local Territorial Knowledge Dynamics in the Swiss Watch Industry, International Journal of Innovation and Regional Development 3(1), 26-44.

Jeannerat, H. and Kebir, L. (2010), Economic Systems of Knowledge and Regions: A Typology Based on the Analysis of Producer-Consumer Relations, DRUID Summer conference, London, accessed at http://www2.druid.dk/conferences/ viewpaper.php?id $=501478 \& \mathrm{cf}=43$.

Kebir, L., Crevoisier, O., Costa, P. and Peyrache-Gadeau, V. (2012), Anchoring, Sustainability and Localisation of Innovation: Towards New Forms of 
Territorialisation of Economic Activities (ASLInn), Final Report, Ecole des ingénieurs de la ville de Paris, Paris.

Krueger, R. and Agyeman, J. (2005), Sustainability Schizophrenia or 'Actually Existing Sustainabilities?' Toward a Broader Understanding of the Politics and Promise of Local Sustainability in the US, Geoforum 36(4), 410-417.

Maskell, P., Bathelt, H. and Malmberg, A. (2006), Building Global Knowledge Pipelines: The Role of Temporary Clusters, European Planning Studies 14(8), 997-1013.

Moulaert, F. and Sekia, F. (2003), Territorial Innovation Models: A Critical Survey, Regional Studies 37(3), 289-302.

Ng, I.C.L. and Yip, N.K.T. (2010), Theoretical Foundations in the Pricing of Intermediating Services: The Case of Payments via Mobile Phones, Journal of Revenue and Pricing Management 9(3), 217-227.

OECD (2009), Sustainable Manufacturing and Eco-Innovation: Towards a Green Economy, OECD Policy Brief, OECD Observer, June, OECD Publishing, Paris.

Osterwalder, A. and Pigneur, Y. (2013), Business Model Generation: A Handbook for Visionaries, Game Changers, and Challengers, Wiley, Hoboken, NJ.

Peyrache-Gadeau, V., Crevoisier, O., Kebir, L. and Costa, P. (2010), Ancrage et durabilité: Pierres angulaires de l'analyse des dynamiques territoriales, Report for a research undertaken for the PUCA - French Ministry of ecology, energy, sustainable development and of the sea, Convention $n^{\circ} \mathrm{D} 08.25$ (0005265).

Smith, A., Vob, J.-P. and Grin, J. (2010), Innovation Studies and Sustainability Transitions: The Allure of the Multi-Level Perspective and its Challenges, Research Policy 39, 435-448.

Späth, P. and Rohracher, H. (2012), Local Demonstrations for Global Transitions: Dynamics across Governance Levels Fostering Socio-Technical Regime Change towards Sustainability, European Planning Studies 20(3), 461-479.

Stark, D. (2011), What's Valuable?, in Beckert, J. and Aspers, P. (eds), The Worth of Goods: Valuation and Pricing in the Economy, Oxford University Press, Oxford, 319-338.

Theurillat, T. and Crevoisier, O. (2012), Sustainability and the Anchoring of Capital: Negotiations Surrounding Two Major Urban Projects in Switzerland, Regional Studies 48(3), 501-515.

Truffer, B. and Cohen, L. (2012), Environmental Innovation and Sustainability: Transitions in Regional Studies, Regional Studies 46(1), 1-21.

Vollenbroek, F.A. (2002), Sustainable Development and the Challenge of Innovation, Journal of Cleaner Production, 10, 215-223.

Zuindeau, B. (2006), Spatial Approach to Sustainable Development: Challenges of Equity and Efficacy, Regional Studies 40(5), 459-470. 